\title{
A 03-months old boy presented with pale stool, jaundice and gradual abdominal distension since birth
}

\author{
Md Nazmul Hassan, Ferdous Ara Begum, Md Nazmul Ahamed, Khan Lamia Nahid, \\ Mohammad Kamal, Sharmin Quddus
}

\begin{tabular}{|c|c|}
\hline Article Info & \\
\hline $\begin{array}{l}\text { Department } \\
\text { Gastroenterology } \\
\text { Bangabandhu Sh } \\
\text { University (BSMM } \\
\text { (MNH, FAB, MNA, } \\
\text { Pathology, Banga } \\
\text { Medical Universit } \\
\text { Bangladesh (MK); } \\
\text { NINMAS, Bangab } \\
\text { Medical Universit } \\
\text { Bangladesh (SQ). }\end{array}$ & $\begin{array}{l}\text { Pediatric } \\
\text { and Nutrition, } \\
\text { kh Mujib Medical } \\
\text { ), Dhaka, Bangladesh } \\
\text { KLN); Department of } \\
\text { andhu Sheikh Mujib } \\
\text { (BSMMU), Dhaka, } \\
\text { cintigraphy Division, } \\
\text { dhu Sheikh Mujib } \\
\text { (BSMMU), Dhaka, }\end{array}$ \\
\hline $\begin{array}{l}\text { For Corresponden } \\
\text { Md. Nazmul Hassa } \\
\text { Email: }\end{array}$ & \\
\hline $\begin{array}{l}\text { Received: } \\
\text { Accepted: } \\
\text { Available Online: }\end{array}$ & $\begin{array}{r}15 \text { January } 2021 \\
17 \text { April } 2021 \\
30 \text { November } 2021\end{array}$ \\
\hline $\begin{array}{ll}\text { ISSN: } 2224-7750 \\
\\
2074-2908\end{array}$ & $\begin{array}{l}\text { nline) } \\
\text { int) }\end{array}$ \\
\hline
\end{tabular}

DOI: https://doi.org/10.3329/bsmmuj.v14i3.56605

Keywords: Neonatal cholestasis, biliary atresia, obstructive jaundice

Cite this article:

Hassan MN, Begum FA, Ahamed MN, Nahid KL, Kamal M, Quddus S. A 03-months old boy presented with pale stool, jaundice and gradual abdominal distension since birth. Bangabandhu Sheikh Mujib Med Univ J. 2021; 14(3): $92-98$

\section{Copyright:}

The copyright of this article is retained by the author(s) [Atribution CC-By 4.0]

Available at:

www.banglajol.info

A Journal of Bangabandhu Sheikh Mujib Medical University, Dhaka, Bangladesh

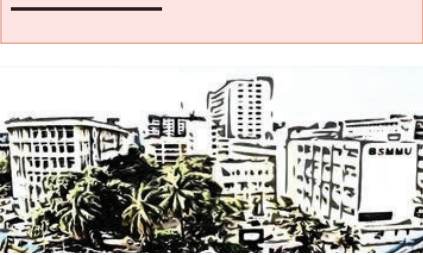

\section{Case Presentation}

Dr. Ferdous Ara Begum (Resident): A-03

months old boy, weighed $4 \mathrm{~kg}$, 1st issue of non-consanguineous parents, presented in our pediatric Gastroenterology department with the complaints of jaundice, persistent pale stool, and dark urine since birth. He had no maternal history of fever, rash during the antenatal period; he was born by LUCS at term with good birth weight. He had no history of delayed passage of meconium or constipation after birth, no history of jaundice of other family members. On examination, he was well alert, active, no facial dysmorphism, moderately icteric, mildly pale, no lymphadenopathy or skin rash, no cataract, all vital signs were normal. The anthropometry revealed no abnormalities on the CDC growth chart. Per abdominal examination revealed, the abdomen was distended, hepatomegaly- $4 \mathrm{~cm}$ from the right costal margin, spleen enlarge- $3 \mathrm{~cm}$ and other systems including eye evaluation revealed no abnormalities.

Laboratory and radiological investigation showed (Table-1) direct hyperbilirubinemia, raised ALT, raised alkaline phosphatase, gamma-glutamyl transferase (GGT) was also raised, prothrombin time (PT) and international normalized ratio (INR) was raised, complete blood count (СBC) showed anemia, leukocytosis, lymphocytosis, thrombocytosis, and peripheral blood film showed microcytic hypochromic anemia. TORCH screening was negative. Ultrasonography of the hepatobiliary system revealed uniform liver parenchyma, normal common bile duct and intrahepatic biliary channels (not dilated) and cholelithiasis (cholesterol calculi) in the gall bladder. (Figure -1)

Prof Dr. Sharmin Quddus: Hepatobiliary scintigraphy (HIDA scan) was done to see the patency of biliary tract which is usally obstructed in biliary atresia and in our case revealed tracer activity within the bowel loops were seen in the delayed views which excluded biliary atresia.

MRCP showed stricture at the proximal common bile duct is noted while the common hepatic duct was dilated $(1.5 \mathrm{~cm}$ in diameter), biliary sludge was noted in the gallbladder lumen. The gallbladder wall was thickened with pericholecystic edema, intrahepatic bile ducts including the main hepatic ducts were prominent. (Figure - 2)

Prof Mohammad Kamal: Liver biopsy showed normal hepatic lobular architecture with no bile plugging or bile stasis.(Figure -3)

\section{Provisional diagnosis}

Neonatal cholestasis most probably due to biliary atresia

\section{Neonatal Cholestasis:}

Md Nazmul Hassan (Resident): Neonatal cholestasis is characterized by conjugated hyperbilirubinemia that occurs in the newborn or shortly thereafter. ${ }^{1}$ Cholestasis is defined physiologically as a measurable decrease in bile flow, pathologically as the histological presence of bile pigment in hepatocytes and bile ducts, and clinically as the accumulation in blood and extrahepatic tissues of substances normally excreted in bile (e.g. bilirubin, bile acids, and cholesterol).2,3 Rather than referring strictly to the neonatal period the term "neonatal cholestasis" is often used to refer to the presence of cholestatic liver disease at birth or develops within the first three months of life. Clinically cholestasis usually presents within the first two months of life. ${ }^{1,3,4}$ Jaundice, dark urine, pale stool, and hepatomegaly are the cardinal features of neonatal cholestasis. Diagnosis is confirmed when direct or conjugated hyperbilirubinemia of more than $1 \mathrm{mg} / \mathrm{dl}$ if total serum bilirubin is $\leq 5 \mathrm{mg} / \mathrm{dl}$, or direct bilirubin 
fraction $>20 \%$ of total bilirubin when the latter is $>5 \mathrm{mg} / \mathrm{dl} .^{3,5}$ Incidence of neonatal cholestasis is 1 in 2500-5000 live births.

Among the many conditions that cause neonatal cholestasis, biliary atresia accounts for approximately $25 \%$ of cases, genetic disorders for another $25 \%$, metabolic disease for $20 \%$, idiopathic neonatal hepatitis for 15\%, a 1-antitrypsin deficiency for $10 \%$, and viral illness for $5 \%$ cases. ${ }^{3,6}$ Biliary atresia (BA) is a progressive idiopathic, necro-inflammatory fibrosing cholangiopathy of unknown etiology involving the extra-hepatic biliary tree which can be either segmentally or entirely, that leads to complete obstruction of the extra-hepatic bile duct during the first few months after birth, progressive biliary cirrhosis, and eventual death if left untreated. It is more common in Asians and African Americans, with slight female predominance. Most infants present with the classical features of jaundice, persistent acholic stools, dark urine, and hepatomegaly. Biliary atresia accounts for approximately $25 \%$ of all cholestasis. ${ }^{3,7}$

It is progressive and the typical features are persisting jaundice, pale stool and dark urine in an otherwise healthy infant and sometimes maybe other uncommon presentation like bleeding tendency due to vitamin $\mathrm{K}$ deficiency, but actual signs of chronic liver disease such as portal hypertension, ascites, and splenomegaly take time to develop (>3 months). ${ }^{8}$ To diagnose ultrasonography of HBS, biochemical liver function tests, absence of bile in the intestine by hepatobiliary scintigraphy (HIDA), and characteristic percutaneous liver biopsy findings includes bile duct proliferation, formation of bile plug, portal fibrosis, and normal hepatic architecture are needed $3,9,10$

\section{Differential Diagnosis}

\section{TORCH infection:}

Md Nazmul Ahamed (Resident): Patients with TORCH infection can present with cholestasis, abdominal distension, organomegaly, and developmental delay which are similar to our patients' clinical features. So, the TORCH infection will be one of the differential diagnoses. The well-recognized acronym TORCH in the field of neonatal/perinatal medicine is very common \& it includes five perinatal infections : Toxoplasmosis, Other (syphilis), Rubella, Cytomegalovirus (CMV) \& Herpes simplex virus (HSV). ${ }^{11}$ Infections with TORCH are acquired transplacentally and the severity of fetal infection depends on the time during pregnancy when maternal infection occurs. Maternal infection may be asymptomatic and not diagnosed until the baby becomes ill. ${ }^{12}$ Intrauterine infection by the TORCH can cause congenital malformations of the central nervous system, intracranial calcification, microcephaly, hydrocephalus, visual defect and deafness in addition to other malformations like congenital heart disease. Only 5\% of them may develop complications like anemia, thrombocytopenia, jaundice, hepatomegaly, maculopapular rash, CNS sequelae etc. ${ }^{12,13}$ The diagnosis of infection is based on the clinical features, antibody detection and virus isolation by the PCR method. ${ }^{13,14}$

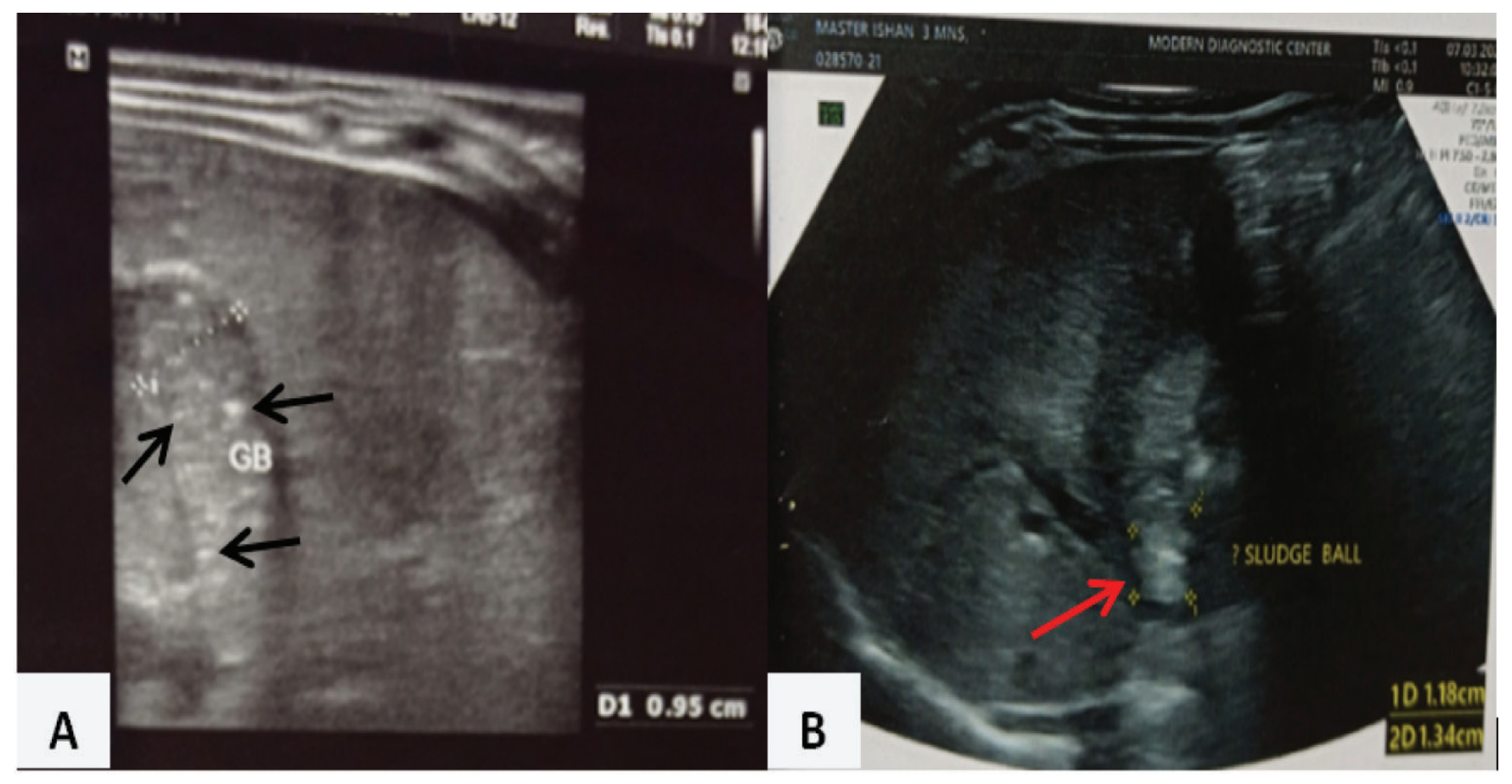

Figure 1: Ultrasonography of the hepatobiliary system : Uniform liver parenchyma, normal common bile duct and intrahepatic biliary channels and cholelithiasis (cholesterol calculi) in the gall bladder. 
Table-I

Laboratory and radiological investigation

\begin{tabular}{|c|c|c|}
\hline Investigations & Results & Reference \\
\hline \multicolumn{3}{|l|}{ Complete Blood Count: } \\
\hline $\mathrm{Hb}(\mathrm{g} / \mathrm{dL})$ & 10.4 & $13-17$ \\
\hline ESR (mm in 1st hr) & 11 & $0-10$ \\
\hline WBC (/mm3) & 16,000 & $4,500-11,000$ \\
\hline Neutrophils (\%) & $18 \%$ & $40-80$ \\
\hline Lymphocyte (\%) & $75 \%$ & $20-40$ \\
\hline Platelet (/mm3) & $4,30,000$ & $150000-4,00,000$ \\
\hline \multicolumn{3}{|l|}{ Liver function tests: } \\
\hline Total bilirubin $(\mathrm{mg} / \mathrm{dl})$ & 7.9 & $<1.1$ \\
\hline Direct bilirubin (mg/dl) & 6.6 & $0-0.2$ \\
\hline Indirect bilirubin (mg/dl) & 1.3 & $0-0.8$ \\
\hline Serum albumin $(\mathrm{gm} / \mathrm{L})$ & 41 & 35 \\
\hline Prothrombin Time (sec) & 98.80 & $12.00-16.00$ \\
\hline International normalized ratio & 11.27 & $<1.4$ \\
\hline Alanine aminotransferase (U/L) & 49 & $10-45$ \\
\hline Serum Alkaline Phosphatase (U/L) & 862 & $40-190$ \\
\hline Gamma-glutamyl & 167 & $<73$ \\
\hline \multicolumn{3}{|l|}{ transferase (GGT) U/L } \\
\hline Serum Creatinine $(\mathrm{mg} / \mathrm{dl})$ & 0.52 & $0.9-1.3$ \\
\hline FT4 pmol/L & 17.4 & $9-19.5$ \\
\hline TSH microIU/L & 1.37 & $0.27-4.2$ \\
\hline \multicolumn{3}{|l|}{ TORCH IgG and IgM } \\
\hline Anti-cytomegalovirus IgM & Negative & \\
\hline Anti-cytomegalovirus IgG & Negative & \\
\hline Anti HSV type 1 IgM \& IgG & Negative & \\
\hline Anti HSV type 2 IgM \& IgG & Negative & \\
\hline Reticulocyte count & $2.88 \%$ & $<2.5 \%$ \\
\hline Ultrasonography of abdomen & \multicolumn{2}{|c|}{$\begin{array}{l}\text { The gallbladder is moderately distended. The wall of the gallbladder appears thick } \\
\text { and edematous, which is } 5.0 \mathrm{~mm} \text { (range is } 1-3 \mathrm{~mm} \text { ). There are multiple tiny stones of } \\
\text { size } 03 \mathrm{~mm} \text { in diameter and smaller seen within the gall bladder. The common bile duct } \\
\text { has an intraluminal diameter of } 8.0 \mathrm{~mm} \text { (range is } 1-2 \mathrm{~mm} \text { ). It is largely dilated. } \\
\text { Ill-defined ovoid echogenic area of size } 13 \times 11 \mathrm{~mm} \text { at the junction of the mid and distal } \\
\text { common bile duct. This may be a sludge ball or soft tissue area in this region. }\end{array}$} \\
\hline Hepatobiliary scintigraphy & \multicolumn{2}{|c|}{$\begin{array}{l}\text { Liver showing homogenous tracer concentration. Significant clearance of cardiac } \\
\text { blood pool activity is seen after } 25 \text { minutes image. Gall bladder and bile ducts are } \\
\text { visualized. Tracer activity within the bowel loops is seen in the delayed views. }\end{array}$} \\
\hline $\begin{array}{l}\text { Magnetic resonance } \\
\text { cholangiopancreatography }\end{array}$ & \multicolumn{2}{|c|}{$\begin{array}{l}\text { Stricture at the proximal common bile duct is noted while the common hepatic duct is } \\
\text { dilated (1.5 cm in diameter), biliary sludge is noted in the gallbladder lumen. The rest } \\
\text { of the common bile ducts were normal. The gallbladder wall is thickened with } \\
\text { pericholecystic edema, intrahepatic bile ducts including the main hepatic ducts are } \\
\text { prominent (Figure 2). }\end{array}$} \\
\hline Liver biopsy & \multicolumn{2}{|c|}{ Normal hepatic lobular architecture with no bile plugging or bile stasis (Figure 3). } \\
\hline
\end{tabular}




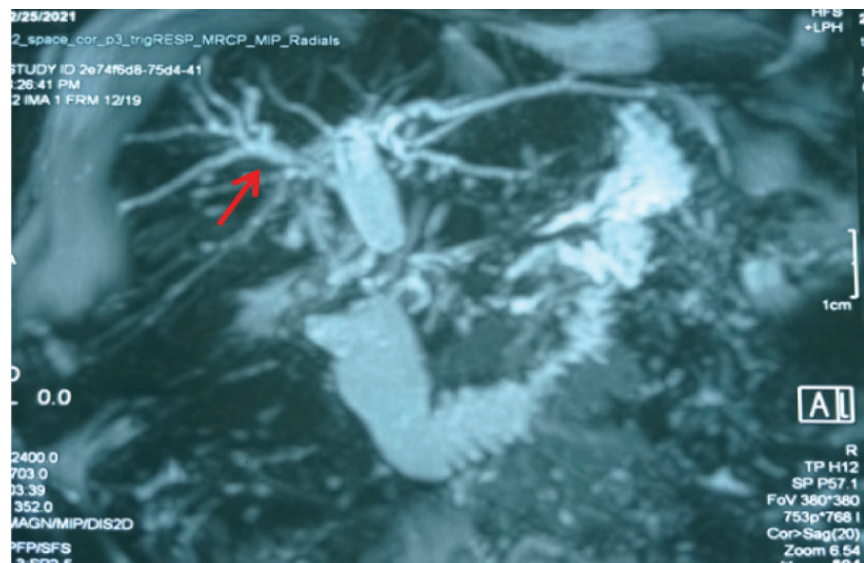

Figure 2: Dilated common hepatic duct (red arrow), stricture at the proximal common bile duct \& also biliary sludge is noted in the gallbladder lumen.

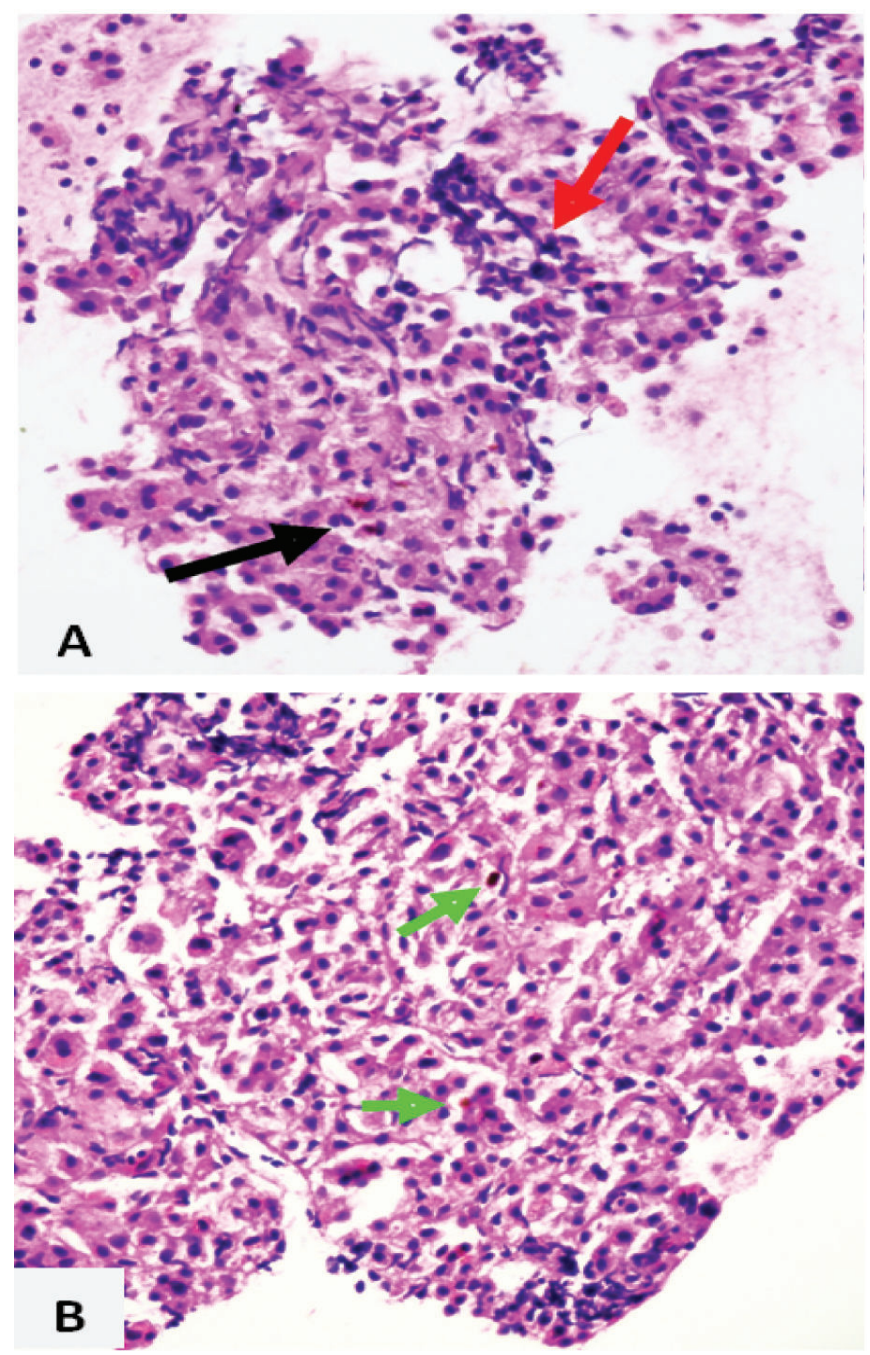

Figure 3: [A] Liver fragment showing tiny focus of cholestasis (black arrow) and a portal area (red arrow). [B] Showing the tiny foci of cholestasis and bile plug of cholestasis (Green arrow) (H\&E x 120).
Idiopathic neonatal hepatitis:

Dr. Ferdous: As the patient was having jaundice, pale stool, dark urine and hepato-splenomegaly we also thought about idiopathic neonatal hepatitis. The term neonatal hepatitis has been used at times to include all causes of cholestasis in infancy in which extra-hepatic biliary obstruction is excluded. Histologically, there is a loss of the lobular architecture and ballooning degeneration of hepatocytes with the fusion of hepatocyte membranes and nuclear transformation into multinucleated giant cells (Giant cell hepatitis). When no infectious, genetic, metabolic, and anatomic cause is identified it is termed as Idiopathic neonatal hepatitis (INH) ${ }^{15}$ Idiopathic neonatal hepatitis was the most common diagnosis in older series, with a reported incidence of INH accounts for $15 \%$ of all cholestasis and 1 in 4800-9000 live births. ${ }^{3,9}$

Dr. Hassan: After evaluating the patient's presenting features and physical findings, this issue of persistent pale stool, jaundice, dark urine, and hepato-splenomegaly favoured the differential diagnosis of BA and TORCH infection. But, our patient had no maternal history of fever, rash during the antenatal period, microcephaly, any eye abnormality, rather the baby was otherwise healthy. Also, the negative TORCH screening and other laboratory parameters excluded TORCH infections. Although clinical features were suggestive of BA but HIDA Scan, ultrasonography, and liver biopsy findings excluded BA. As we found the specific cause of the neonatal cholestasis by MRCP and Ultrasonography, so the diagnosis of INH was also excluded.

\section{Final diagnosis:}

Dr. Hassan's Diagnosis: Neonatal Cholestatasis due to choledochal cyst (Type IA) with cholelithiasis.

\section{Discussion}

Dr Khan Lamia Nahid (Assistant professor): Neonatal cholestasis is an uncommon but potentially serious problem that indicates hepatobiliary dysfunction, affects approximately 1 in every 2500 term infants. ${ }^{3}$ Cholestasis is defined as reduced bile formation or flow resulting in the retention of biliary substances within the liver which is normally excreted into bile. Cholestasis is usually recognized by elevation of serum conjugated (direct) bilirubin. So, Neonatal cholestasis is a disease of conjugated hyperbilirubinemia of infants manifesting within 03 months of life presenting as jaundice, pale stool, dark urine, and hepatomegaly. ${ }^{16} \mathrm{NC}$ is considered when the conjugated bilirubin level exceeds $1 \mathrm{mg} / \mathrm{dL}$ with a total bilirubin level $\leq 5 \mathrm{mg} / \mathrm{dL}$ or when the conjugated bilirubin is $\geq 20 \%$ of the total bilirubin that is $>5 \mathrm{mg} / \mathrm{dL}$. NC can be due to either intra/extra-hepatic bile duct (IHBD/EHBD) 


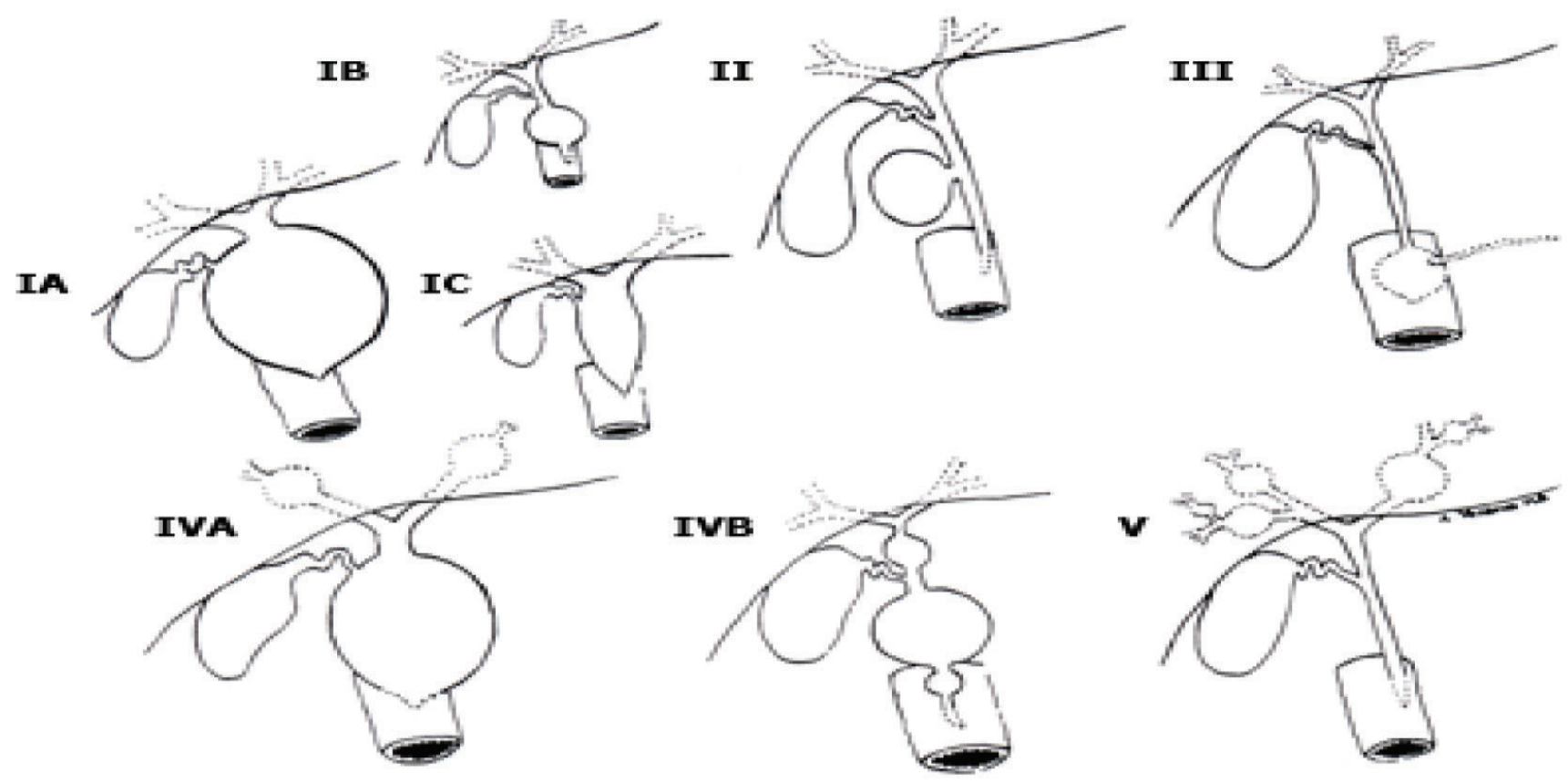

Figure 4: Classification of choledochal cyst: (IA) Common cystic type, (IB) Focal \& segmental dilatation, (IC) Fusiform dilatation of extra-hepatic duct, (II) Diverticulum, (III) Choledochocele, (IVA) Multiple cysts (intra- and extrahepatic), (IVB) Multiple cysts (extrahepatic) \& (V) Single or multiple dilatations of the intrahepatic ducts

cause is Biliary atresia. Choledochal $\operatorname{cyst}(\mathrm{CC})$ is the second most common surgically correctable cause. ${ }^{17}$

CC is congenital anomalies of the biliary tract manifested by intraand/or extrahepatic biliary dilatation. ${ }^{17}$ In 1723 choledochal cyst was first described by Vater and Ezler. ${ }^{18}$ It is commonly found in the Asian population with female preponderance (4:1), with an incidence of 1 in 13,000 and 1 in 100,000 population in Asian and western population respectively. ${ }^{17,19}$

The understanding of the exact etiology of CC formation has remained incomplete and is usually thought to be congenital but some hypotheses present. ${ }^{17,20}$ Common hypothesis is an anomalous pancreaticobiliary union (APBDU) which is a union between pancreatic and biliary ducts outside of the duodenal wall and proximal to the Ampulla of Vater ${ }^{21}$, and in absence of APBDU underlying pathophysiology includes weak bile duct wall, distal biliary obstruction or sphincter of Oddi dysfunction. ${ }^{17,22}$

The clinical presentation of CC in neonate and infancy $(<1$ year) varies from pediatric and older children and it may be a separate entity as it has different clinical and radiologic presentations and may have separate etiologies. ${ }^{23,24}$

Neonatal CC may be associated with distal biliary atresia and typically present with obstructive jaundice and acholic stool. ${ }^{17,24}$ Jaundice mainly occurs in type I and IV CC. ${ }^{23}$ Infants with CC usually present with jaundice, clay-colored stools and in the pediatric patient, the classical presentation is intermittent jaundice, abdominal pain, and palpable right upper quadrant mass. ${ }^{23}$ In our case, the child presents with obstructive jaundice and acholic stool, and also slight atresia or stricture of the common bile duct is seen in imaging.

According to Todani and colleagues, CC has five categories [Figure 4] that include (IA) Cystic dilation of the common bile duct, (IB) Focal, segmental dilation of an extrahepatic bile duct (often the distal common bile duct), (IC) Smooth, fusiform dilation of all the extrahepatic bile ducts, (II) Diverticulum, (III) Choledochocele, (IVA) Multiple cysts (intra- and extrahepatic), (IVB) Multiple cysts (extrahepatic) \& (V) Single or multiple dilatations of the intrahepatic ducts. ${ }^{17,25}$ In our case there is a cystic dilatation of the common bile duct present, so it is a type IA choledochal cyst.

Choledochal cyst usually can be detected by ultrasonography and should be further evaluated by magnetic resonance cholangiopancreatography (MRCP), endoscopic retrograde cholangiopancreatography (ERCP), and/or intraoperative cholangiopancreatography to see the extent of ductal involvement. ${ }^{17,26}$ Both ultrasound and CT are highly sensitive and specific for the diagnosis of CC. If there is no intrahepatic biliary dilation, then ultrasonography alone is sufficient for diagnosis but MRCP is better able to delineate $\mathrm{CC}$ subtype and associated abnormalities. ${ }^{27}$

There is an important differential of CC is the cystic type of biliary atresia and both have different management approaches and prognoses. ${ }^{16}$ Biliary cysts must be differentiated from cystic biliary atresia because if the cystic 
biliary atresia left untreated it can cause the death of the patient within 02 years of age due to progressive liver cirrhosis, whereas CC can have an excellent prognosis with resection of the cyst and hepaticojejunostomy. ${ }^{16,28}$

Patients with larger cysts dilated intrahepatic ducts, and normal gallbladder are more likely to have choledochal cysts. Inversely, those with smaller cysts, nondilated intrahepatic ducts, abnormal gallbladder are more likely to have cystic biliary atresia. ${ }^{16}$ In our case, the patient has dilated intrahepatic ducts and no triangular cord signs on USG. We did hepatobiliary scintigraphy and percutaneous liver biopsy and the findings exclude cystic type biliary atresia.

Recurrent cholangitis, cirrhosis, portal hypertension, liver failure, stone formation, pancreatitis, and malignant transformation are the long-term complications of untreated choledochal cysts. ${ }^{29}$ In our patient gall bladder stone present as well as biliary sludge present, it may be due to stasis of the biliary channel secondary to choledochal cyst as well as the presence of cholestasis.

Management is according to the type of CC and presence of complication. The establishment of free bile drainage by Roux en-Y hepaticojejunostomy for biliary reconstruction and Total excision of the CC has been widely accepted as a standard surgical procedure even for infants and children. ${ }^{29}$ We transfer the patient for surgical management in the pediatric surgery department.

Neonatal cholestasis due to Choledochal cysts is relatively rare \& it is different between patients less than and more than 1 year of age. To prevent long-term complications such as biliary cirrhosis and cyst rupture, surgery should be done as soon as possible in patients younger than 1 year.

Dr Ayesha Siddiqua (Resident): Can you clinically say it is a case of TORCH infection?

Dr Md Nazmul Ahamed(Resident) : TORCH infections may present with cholestasis, hepatosplenomegaly, microcephaly, and developmental delay and as our patient presented with these features, so we initially thought about TORCH infection but absence of characteristic maternal history, other features like microcephaly, cardiac anomaly \& sensory-neural deafness and also the absence of serological evidence we exclude it. ${ }^{12,13}$

Dr. Urmi Roy (Resident): What is the specific diagnostic modality of choledochal cyst?

Dr. Sharmistha Ghosal (Resident): Ultrasonography is the investigation of choice for diagnosis of CC but it can classify it, so for further evaluation and also management purpose we have done MRCP. ${ }^{17}$

Dr. Umma Jannatul Ferdous (Resident): How you will differentiate cystic biliary atresia and CC?

Dr. Nahid-E-Subha (Fellowship course): The clinical presentation of neonatal CC and cystic biliary atresia is usually the same. So we can differentiate it by USG, Hepatobiliary scintigraphy, and finally a liver biopsy. Triangular cord sign, absent or abnormal gall bladder, and absence of intrahepatic dilatation are characteristic of biliary atresia. ${ }^{28}$

Dr. Ranjit Kumar (Resident): Why did you do a HIDA scan?

Dr. Benzamin (Resident): Hepatobiliary scintigraphy is an important investigation to see the patency of the biliary channel. The absence of radiotracer activity in the intestinal lumen is suggestive of biliary atresia.

Dr. Badrun Nahar (Resident): Why you have done a liver biopsy?

Dr. Sharmistha Ghosal (Resident): For diagnosis of CC liver biopsy is not compulsory. But we have done a liver biopsy to exclude biliary atresia and as well as to see any features of cirrhosis. Bile ductular proliferation, formation of bile plug, portal fibrosis, and normal hepatic architecture are the characteristic features of biliary atresia in liver biopsy. $3,9,10$

Dr. Farhana Bayes (Resident): What may be the cause of cholelithiasis?

Dr. Md. Saidul Islam Sumon (Resident): Transient biliary sludge followed by the formation of gall stones can develop during the neonatal period, the majority of which clear by 6 weeks postpartum. It may occur due to cystic fibrosis, bile duct malformations including strictures and choledochal cysts, total parenteral nutrition, hormonal fluctuation, or medication use. ${ }^{30}$ In our case, it may be due to prolong biliary stasis secondary to CC in the common bile duct.

Dr. Rafiqul Islam (Resident): What are the treatment modalities in your case?

Dr. Ahmadur Rahman (Resident): Management is depending on the type and presence of complication of CC. In the case of exclusive extrahepatic CC total surgical excision along with biliary channel reconstruction is the modality of choice and it is curable if there is no prior development of cirrhosis.

\section{References}

1. Sira MM, Sira AM, Elhenawy IA, Khalil FO. Prevalence of serological markers of TORCH infections in biliary atresia and other neonatal cholestatic disorders. Peertechz J Pediatr Ther. 2016; 2(1): 013-017.

2. Feldman A, Suchy F. Approach to the infant with cholestasis. In: Suchy Frederick J, Sokol Ronald J, Balistreri William F, editors. Liver disease in children. Cambridge: Cambridge University Press; 2014. p. 101-137.

3. Benzamin M, Hassan N, Begum F, Tasmeen R, Islam MR. Neonatal cholestasis: evaluation and management. Paed. Neph. J. Bang. 2019; 4(2): 109-16.

4. Sokol RJ, Mack C, Narkewicz MR, Karrer FM. Pathogenesis and outcome of biliary atresia: current concept. J Ped Gastroenterol Nutri. 2003; 37:4-21. 
5. Feldman AG, Sokol RJ. Neonatal cholestasis. Neoreviews. 2013;14(2):e63-73.

6. Balistreri WF, Bezerra JA. Whatever happened to "neonatal hepatitis"? Clin Liver Dis. 2006; 10:27-53.

7. Balistreri WF. Neonatal cholestasis. J Pediatr. 1985; 106:171-184.

8. Lakshminarayanan B, Davenport M. Biliary atresia: a comprehensive review. J Autoimmun. 2016; 73:1-9.

9. Moyer V, Freese DK, Whitington PF, Olson AD, Brewer F, Colletti RB, Heyman MB. Guideline for the evaluation of cholestatic jaundice in infants: recommendations of the North American Society for Pediatric Gastroenterology, Hepatology and Nutrition. J Pediatr Gastroenterol Nutr. 2004; 39:115-128.

10. Guan YX, Chen Q, Wan SH, Huang JS, Yang XQ, Pan LJ, Zhang QI, Zhang Q, Ou YJ, Peng XW, Liu SZ. Effect of different time phases of radionuclide hepatobiliary scintigraphy on the differential diagnosis of congenital biliary atresia. Genet Mol Res. 2015; 14(2):3862-8.

11. Maldonado YA, Nizet V, Klein JO, et al. Current concepts of infections of the fetus and newborn infant. In: Infectious Diseases of the Fetus and Newborn Infant, 7th ed, Remington JS, Klein JO, Wilson CB, et al (Eds), Elsevier Saunders, Philadelphia 2011. p.2.

12. Nahar L, Karim ASMB, Biswas SA, Mondal M, Dey BP. A 3 year old girl presented with abdominal distention since birth with developmental delay. Bangabandhu Sheikh Mujib Med Univ J. 2018; 11: 261-266.

13. Yadav RK, Maity S, Saha S. A review on TORCH: Groups of congenital infection during pregnancy. J Sci Innov Res. 2014; 3: 258-64.

14. Fatollahpour A, Karbassi G, Roshani D, Ramezany P, Mohammadbeigi R. Sero epidemiological study of TORCH infection in women of childbearing age in West of Iran. Res J Pharm Biol Chem Sci. 2016; 7: 1460-65.

15. Philip Rosenthal. Neonatal hepatitis and congenital infection. Cholestatic liver disease. Suchy Frederick J, Sokol Ronald J, Balistreri William F, editors. Liver disease in children. Cambridge: Cambridge University Press; 2014. p. 131

16. Zhou LY, Guan BY, Li L, Xu ZF, Dai CP, Wang W, Xia HM, Xie XY. Objective differential characteristics of cystic biliary atresia and choledochal cysts in neonates and young infants: sonographic findings. J Ultrasound Med. 2012; 31(6):833-41.

17. Soares KC, Goldstein SD, Ghaseb MA, Kamel I, Hackam DJ, Pawlik TM. Pediatric choledochal cysts: diagnosis and current management. Pediatr Surg Int. 2017; 33(6):637-50.
18. Vater A, Ezler C. Dissertatio de scirrhis viserum occasione sections viri typanite defunte. Wittenburgae, 4 Pamphlers. $1723 ; 881: 22$

19. Soares KC, Arnaoutakis DJ, Kamel I, Rastegar N, Anders R, Maithel S, Pawlik TM. Choledochal cysts: presentation, clinical differentiation, and management. J Am Coll Surg. 2014; 219(6):1167-80.

20. Babbit DP. Congenital choledochal cyst: new etiological concept based on anomalous relationships of the common bile duct and pancreatic bulb. Ann Radiol. 1969; 12:231-40.

21. Ono S, Fumino S, Iwai N. Diagnosis and treatment of pancreaticobiliary maljunction in children. Surg today. 2011; 41(5):601-5.

22. Martin RF. Biliary cysts: a review and simplified classification scheme. Surg Clin North Am. 2014; 94(2): 219-32.

23. Hung MH, Lin LH, Chen DF, Huang CS. Choledochal cysts in infants and children: experiences over a 20-year period at a single institution. Eur J Pediatr. 2011; 170(9):1179-1185.

24. Torrisi JM, Haller JO, Velcek FT. Choledochal cyst and biliary atresia in the neonate: imaging findings in five cases. AJR. Am J Roentgenol. 1990; 155(6):1273-6.

25. Todani T, Watanabe Y, Narusue M, Tabuchi K, Okajima K. Congenital bile duct cysts: classification, operative procedures, and review of thirty-seven cases including cancer arising from choledochal cyst. Am J Surg. 1977; 134(2):263-69.

26. Jiexiong F, Minju L, Hongfeng $\mathrm{T}$, et al. Clinical and pathological characteristics of cystic lesions of extrahepatic bile duct in neonates. Acta Paediatr. 2003; 92:1183.

27. Sacher VY, Davis JS, Sleeman D, Casillas J. Role of magnetic resonance cholangio-pancreatography in diagnosing choledochal cysts: Case series and review. World J Radiol.2013; 5(8):304-312.

28. Kim WS, Kim IO, Yeon KM, Park KW, Seo JK, Kim CJ. Choledochal cyst with or without biliary atresia in neonates and young infants: US differentiation. Radiology. 1998; 209:465-469.

29. Chen CJ. Clinical and operative findings of choledochal cysts in neonates and infants differ from those in older children. Asian J Surg. 2003; 26(4):213-7.

30. Brownschidle S, Sullivan J, Sartorelli K, Potenta S, Zenali M. Neonatal cholestasis due to biliary sludge-review and report of a case associated with use of diflucan. Ann Clin Path. 2014; 2(2):1018. 